\title{
Cultural Differences between China and the West and Its Enlightenments to the College English Teaching
}

\author{
Baohua Yan \\ Teaching and Research Institute of Foreign Languages, Bohai University, Jinzhou, 121013, China \\ yanbaohua2008@163.com
}

Keywords: China and the West; cultural differences; college English teaching; enlightenment

\begin{abstract}
Language and culture are interdependent and interact with each other. Only when we fully understand the culture represented by the language, can we master the language better. The differences between Chinese and Western cultures are reflected in the ways of thinking, value orientation, ethics and behavior, and so on, which have an impact on College English Teaching in listening, speaking, reading, writing and translation. The results of previous studies, from the differences between Chinese and Western culture is proposed for College English teaching are as follows: the textbooks in cultural phenomenon, pay attention to cultural differences; understand the historical development of the English language, improve cultural accomplishment; change the concept of teaching, encourage students to increase the amount of reading; cultural penetration, cross culture ability; The use of comparative teaching methods to enhance students' understanding of cultural differences; the use of cultural teaching methods to enhance cultural differences.
\end{abstract}

\section{Introduction}

Professor Kramsch of the United States pointed out the importance of cultural factors in the process of language teaching, and put forward the multicultural interaction model which should be adopted in teaching [1]. Many scholars in China have also studied the relationship between culture and foreign language learning. At present, most of the College English teaching is based on the basic knowledge of language teaching, teachers use most of the time to teach vocabulary, grammar and test questions, not to focus on cultural factors. In the course of teaching, there is too much reliance on the limited knowledge on the books, and the organic integration of the introduction of the language and the introduction of culture. Most of the students do not have close contact with the British and American culture, foreign teachers are limited to the classroom for a short time, and the level of foreign teachers is generally low, did not really grasp the western culture. With the continuous expansion of teachers' teaching tasks is increasing, not too much time and energy to study and research related to the improvement of their own quality is slow, narrow range of knowledge, master the knowledge of western culture can not meet the needs of students. These reasons directly lead to students' interest in learning English is not strong, the teaching effect is not satisfactory, therefore, the appropriate introduction of cultural differences between China and the west is an effective way to solve these problems.

\section{Cultural Differences between China and the West}

The comparison of Chinese and Western culture, not only has the relations, but also has the different cultural background and the history. Language teaching should pay attention to the similarities and differences between them. The differences between the two are as follows:

(1) Thinking mode difference. The thinking method is the way, the means or the method that the people use the thought activity, in order to realize the purpose of the specific thought, which is the tool and the method used in the thinking process. The difference of philosophical tradition is an important reason for the difference between Chinese and Western ways of thinking. The western philosophy tradition is that the reason is higher than the sensibility, the rational analysis and the positive analysis. China by Taoism and Buddhism, attach importance to comprehension and 
practice, by virtue of experience and knowledge, the essence and laws of objective things to judge, pay attention to the overall harmony; the different geographical environment also leads to the differences between Chinese and Western ways of thinking, different natural environments of different thinking plays a key role. Ocean plays an important role in Western civilization. The common ancestors living in turbulent climate and harsh marine environment, forming a focus on natural and exploring the nature of tradition, with a strong desire to conquer and brave spirits. In contrast, China is continental type relatively closed geographical environment, is rarely the natural damage, pay attention to "heaven" and "heaven, earth and man".

(2) Differences in value orientation. Value orientation refers to some of the values into a certain cultural choice of the concept, or by the individual recognition and internalization into the core structure of the personality, with the evaluation of things, to arouse attitudes, guidance and regulation of directional behavior. Value orientation has practical character, the role is to determine and dominate the value of the main choice. Value orientation has the character of practice, which is the value choice of the subject. The rationalization of value orientation is the belief of human progress. The values of western people think that the individual is the basic point of the society, the center of the self, the individual's way of life and the quality of life depends on their own ability, personal interests are higher than the overall interests of society. Therefore, do not get used to care and help others, but to ask someone else business, to promote the individual should show the personality, the more show their personality, the more reflect the value of life. The value of the Chinese people, emphasizing the sense of community and social consciousness, personal interests to the interests of society as a whole, only the development of society, individuals can get the maximum benefit. In a group, a person's achievement is regarded as a collective achievement. Chinese culture is noble and selfless. Active care is not a virtue, personal competition and hard work consciousness is not strong, there is dependence.

(3) Ethical differences. Ethics is about human nature, human relations and the structure of the basic principle summary. Morality refers to the sum of the norms regulating the relationship between man and man, man and nature. Ethics focuses on reflecting the relations and rules to maintain human relations; the moral category focuses on reflecting the moral activity or moral subject's behavior. Western culture encourages individuals to develop innovation, focus on personal development and honor, proud of the achievements of individuals, never hide their self-confidence, sense of honor and achievement after the ecstasy. The concept of Western family is indifferent, providing the maximum freedom for the young people, and the ability to live independently. Chinese culture is modest and prudent, personal achievements, not that show. Asked golden mean in Chinese traditional culture, worry about innovation risk, always think, weighing around, like everything and Ann, to maintain the status , maintain harmony. Treat the family, like the reunion, family members rely on each other, help each other. This way of life is not conducive to the development of the independent ability of young people.

(4) Behavioral norm difference. Code of conduct is a social group or individuals to participate in social activities to follow the rules, social recognition and was widely accepted, with general binding behavior standard, is to regulate interpersonal communication and implementation tools of social control and maintain social order. When people of different cultural backgrounds communicate with each other, they often apply their own behavioral norms to judge the rationality of the other party's behavior. Because of the differences in the norms of behavior between the two sides, often misunderstood. Western society emphasizes on individual rights as a benchmark, to pursue self-interest as the goal, do not pay attention to the friendship between people, rely on the law to solve the contradiction between people. The law can protect individual rights, but also sanctions against human rights violations. Therefore, the development of the rule of law in western countries is closely related to the values of human rights. Chinese culture due to the influence of traditional Confucianism, by the light, heavy feeling light method. The friendship as the highest standards, not anything. Since ancient times, mainly rely on moral constraints of people's behavior norms and maintain society, rather than relying on the law, therefore, people's legal awareness is relatively weak. 


\section{Influence of Cultural Differences between China and the West to the Language Teaching}

The differences between Chinese and Western cultures have a great influence on College English teaching, especially in listening, speaking, reading, writing and translation.

(1) The influence of listening teaching [2]. Because of the different living environment and material cultural environment in the English speaking countries and the Chinese speaking countries, there are many differences between the two languages. If we do not understand the cultural background knowledge of language, we can not effectively improve the level of English listening. In the teaching of listening, not only the students should have the knowledge of vocabulary, pronunciation and grammar, but also be familiar with the relevant social and cultural knowledge. The cultural background knowledge of listening comprehension is various. The listening materials involved in English speaking countries, customs, norms, political system, religion, history, geography and long, sports and cultural background knowledge in listening comprehension plays a very important role.

(2) Influence on oral English teaching [3]. Is mainly reflected in three kinds of behaviors: one is greeting speech act. Westerners usually greet each other, and then talk about the weather, climate and traffic topics, will not ask questions of privacy. Chinese greeting, usually with each other's situation or trends as the topic; two is to invite language acts. When Westerners invite others, they must specify the specific time, place and content of the activities, and ask the other side to answer, the other party will generally answer and express their gratitude. Chinese invited to repeated several times, but also attach such as "must come" and "Be There Or Be Square" and other words to show sincerity, the other reaction to the invitation is often talk ambiguously three, compliment speech act. Westerners generally receive praise, and expressed their gratitude, very confident. Chinese to compliment and praise, generally used to represent a modest decline.

(3) Influence on reading teaching [4]. English reading involves many aspects of grammar and vocabulary is the basis of reading comprehension, cultural background is the key obstacle to read, if you do not understand the culture of the cultural background knowledge is not accurate grasp, it will affect the reading teaching work smoothly. Western culture affects reading comprehension from four aspects such as words, sentences, paragraphs and paragraphs. To understand western culture, we can strengthen the understanding of vocabulary, strengthen the understanding of sentence structure, promote the grasp of paragraphs, and understand the meaning of discourse. The final goal of reading is to obtain information, to help students understand the author's feelings and intention of writing, reading teaching to the normal development, we must start from the understanding of the cultural environment, grasp the differences between Chinese and Western culture, and constantly improve the level of reading.

(4) On the teaching of writing. Writing is an important part of the output ability of language, and the different ways of thinking between the East and the West are often reflected in the three aspects of discourse, syntax and grammar. At the textual level, the English discourse is linear, and the paragraph structure is mainly linear paragraph structure. In the syntactic and grammatical level, the Westerners pay attention to the ontology, the subject of the sentence can not be omitted, even if there is no subject also need to add; Chinese people do not pay attention to the body, the subject can often be omitted when writing. The number, person and tense in English have mark clear, while the Chinese are not these markers, mainly rely on words or word order to express these concepts. These differences will have a great impact on writing.

(5) Influence on translation teaching [5]. Translation is difficult because language not only carries a rich cultural connotation, but also by cultural constraints. In the process of translation, it is necessary to combine Chinese and Western cultures. If we turn away from the cultural background, it will cause the loss or distortion of cultural images, and produce misunderstanding. In the process of translation, we should not only understand the original meaning of words and sentences, but also make use of the semantic, cultural and historical background to make the language play a role in the transmission of information and communication. It is necessary to take into account the differences of national cultural characteristics and cultural information caused by regional cultural differences. In the process of translation, we should try our best to be faithful to the original text, and to translate 
the different customs and cultures of the destination countries, so as to achieve the purpose of spreading the correct ideas.

\section{Enlightenments of Cultural Differences between China and the West to the College English Teaching}

Based on the differences between Chinese and Western cultures, through the analysis of the influence of Chinese and Western cultural differences on language teaching, combined with other literature, the differences between Chinese and Western culture and its implications for College English teaching are presented:

(1) excavate the cultural phenomenon in the teaching material, pay attention to the cultural difference. The teaching material is an important resource for learning English, and the rich teaching materials reflect the cultural connotation of the language. In the teaching material, from the pronunciation, the glossary to the sentence expression, is permeated with the foreign cultural color. The teachers should have the sensitivity of cross-cultural awareness in the course of preparing lessons, and fully explore the cultural differences in the teaching materials. For example, in about the temperature, usually Chinese degrees Celsius, Americans usually use degrees; English grammar for questions and answers Chinese English is completely different, according to the actual situation of the same answer in Chinese, is to solve the problem and answer. Teachers should focus on the content of the teaching materials to summarize the cultural framework, and to carry out the teaching design, so that language teaching can really achieve the ability to cultivate and improve the effect.

(2) Understand the history of English language development, improve cultural accomplishment. Let students understand the English language in the history of the development process, not only helps to understand and memorize the language phenomenon and language materials, and can help the students to use the appropriate language on different occasions, to improve communication ability. To understand the development and change of English language is helpful to improve students' cultural accomplishment and comprehensive quality. The development of English language is influenced not only by the social and cultural development of native English speaking countries, but also by the social and cultural development of other countries. Knowing this will help learners to use English thinking more quickly. In addition, culture, language and thinking depend on each other, language is the carrier of thinking, and embodies the culture. Therefore, it is necessary for English learners to make a macro comparison of the two languages, to eliminate the influence of thinking and cultural differences in the process of communication.

(3) Change teaching ideas, encourage students to increase the amount of reading. Traditional college English teaching is centered on words and grammar. In the cultivation of intercultural competence, reading plays an irreplaceable role. By reading books on Western cultural background, students can easily understand the characteristics of western culture, understand the customs of Western countries. The students in their spare time can also read the western literary works, or reading some newspapers, news and commentaries on more abundant materials by the subtle influence in the students' information at the same time, the culture of western countries also increased. In the age of electronic information, it provides a wider range of models for English reading. Through reading, we can cultivate students' interest in learning English, but also deepen the understanding and understanding of the western countries' living customs and language habits, and thus improve their intercultural communicative competence.

(4) To carry out cultural infiltration and cultivate cross-cultural competence. Cultural penetration refers to adapt to the external cultural ideology, gradually accept the foreign culture and become the executor and maintainer of culture . Culture is not only common, but also personality. For students, it is easier to grasp the commonness of culture, and the lack of understanding of the differences or personality is easy to cause communication errors. Pay attention to the cultivation of students' intercultural awareness in English teaching so that students in the target language culture to understand correctly, establish cultural relativism view, ruled out with local culture as the benchmark for the evaluation of the exotic culture attitude, certainly all culture has its value view. For foreign cultures should be based on the "horizontal" point of view. In the course of teaching, we 
should follow the principle of cultural differences, penetrate the differences between the target language culture and the native culture, and avoid the mistakes in cross-cultural communication[6].

(5) Using comparative teaching method to improve students' understanding of cultural differences [6]. Contrast teaching method can make students in the face of new knowledge, effectively get rid of strangeness, find a way to easily get started, increase the initiative of learning, improve learning efficiency, optimize the learning effect. Contrast teaching method is helpful to cultivate students' thinking ability, firmly grasp the basic theory and skills, and create a good learning atmosphere. In College English teaching, teachers should be combined with the content of cultural background, cultural connotation and cultural practices, and compared with the Chinese relative culture, help students learn English, understand English culture.

(6) Adopting cultural teaching method to enhance the consciousness of cultural difference. The traditional teaching method of culture teaching only stays at the level of understanding, the students are difficult to produce the actual experience, the cultural knowledge is easy to form the thinking mode, and can not deal with all kinds of situations flexibly in the real communication. From the perspective of the relationship between language and culture, language and culture is an organic whole, which is a kind of "knowledge". At the same time, culture teaching method did not get rid of the drawbacks of cramming teaching, is not conducive to the students to think independently. A single culture teaching method can not meet the teaching needs of English culture, we should adopt flexible teaching methods to stimulate students' interest and enthusiasm in Western culture. There are many methods of culture teaching, teachers should make full use of various ways to improve students' sensitivity to culture, cultivate cultural awareness.

\section{Conclusion}

Language learning is inseparable from the cultivation and edification of cultural awareness. College English teaching should not only focus on pronunciation, vocabulary and grammar, but also introduce the differences between Chinese and Western cultures. Only when we fully understand the culture represented by the language, we can master the language more easily, and can communicate with each other freely.

\section{References}

[1] Y. Du, "The Influence of Cultural Differences on College English Teaching," Journal of Hunan Industry Polytechnic, vol. 12, no. 3, pp. 114-115, 2012.

[2] T. Zhang, " The influence of cultural differences on English listening teaching," Modern Society, vol. 26, no. 8, pp. 251-251, 2012.

[3] C. F. Pang, "The influence of Chinese and Western cultural differences on oral communication," Reading and writing: education and teaching research, vol. 28, no. 41, pp. 286-286, 2012.

[4] Paper nets, "The influence of British and American culture on reading teaching," http://www.xzbu.com/9/view-6137249.htm, 2017-3-5.

[5] J. Zhu, "The influence of Chinese and Western cultural differences on translation," Shanxi Youth, vol. 38, no. 2, pp. 62-62, 2013.

[6] L. Z. Lei, "Cultural differences between Chinese and Western in English Teaching," Journal of Shanxi Normal University(Social Science Edition), vol. 39, no. s2, pp. 159-1606, 2012.

[7] N. Cao, "The significance of cultural differences in College English Teaching," Education Teaching Forum, vol. 8, no. 27, pp. 62-62, 2016. 